\title{
Accessory Renal Blood Vessels as the Potential Risk Factor of Renal Fail- ure for Endovascular Treatment in Abdominal Aortic Aneurysm
}

\section{Zietek-Czeszak A' ${ }^{1}$, Gutowski $\mathbf{P}^{2}$ and Zietek $\mathbf{Z}^{3^{*}}$}

${ }^{1}$ Department of Vascular, Angiology and General Surgery Pomeranian Medical University, Szczecin, Poland

${ }^{2}$ Department of Normal and Clinical Anatomy, Pomeranian Medical University, Szczecin, Poland

${ }^{3}$ Department of General Surgery and Transplantology, Pomeranian Medical University, Szczecin, Poland

\begin{abstract}
Purpose: Despite the advantages of endovascular procedures (EVAR) some authors are doubts to recommend this method for some patients. It main concerns the patients with accessory renal arteries (ARAs) and an increased risk of kidney failure. The aim of this work was to evaluate the impact of accessory renal arteries on the renal complications after EVAR.
\end{abstract}

Methods: 54 of non-randomized patients with ARAs were enrolled to project. The endovascular aneurysm repair (EVAR) was performed in 30 patients and in other 24 classical surgery. 70 patients without ARAs composed the control. Kidney condition was estimated on RIFLE-AKIN classification evaluating concentration of creatinine, urea, glomerular filtration rate (GFR), and urine output per hour (UO). The multivariate regression analysis (ANCOVA test) was applied to correct for confounding and increase of precision of an estimated differences.

Results: The parameters after EVAR procedure did not differ significantly in comparison with preoperative value of urea $(p=0.6)$, creatinine $(p=0.16)$, GFR $(p=0.4)$ and urine output $(p=0.8)$. The ANOVA test revealed also that postoperative parameters in all group of patients did not differ significantly. Although, data in classical approach both with or without ARAs shown a slightly tendency towards renal failure by higher concentration of urea (46.1 vs. 45.1$)$ and creatinine (1.26 vs. 1.21) and lower GFR (61 vs. 66$)$ and urine output per hour $(0.60$ vs. 0.61$)$. In multivariate regression analysis was shown the preoperative renal failure as an independent factor of acute renal injury. According to RIFLE-AKIN algorithm none parameters did not reach the expected postoperative value which allow to diagnose one of the stadia of acute kidney injury.

Conclusions: Based on the results in patients with ARAs but normal function of kidney the EVAR procedure can be considered as the safe method.

Keywords: Aortic aneurysm; Endovascular procedure; Renal failure

\section{Introduction}

Protecting kidney function is a priority of each procedure on the abdominal aorta. It is well established that postoperative kidney complications are severe morbidity which increase up to $20 \%$ postoperative mortality and costs of treatment [1-4]. Despite that protecting major renal arteries seems unquestionable matter there are many unresolved issues concerning accessory renal arteries (ARAs) especially in the treatment of aortic abdominal aneurysms. First, the question arises whether performing endovascular treatment on the abdominal aorta with the presence of accessory renal arteries endangered kidney function [1]. The incidence of acute kidney injury following elective endovascular procedures on the abdominal aorta with the presence of accessory renal arteries is virtually unknown. It could be because of the lack of standardized lab tests and clinical criteria of acute kidney injury [5-7]. Based on current literature it seems that problem of protecting renal artery renal arteries is still open [6,7]. Some authors point out that an attempt to protect accessory renal arteries may increase the risk of the potential end leaks [8]. Therefore, it is essential whether protecting accessory arteries jeopardize the final effect of the treatment [9].

The definition and the criteria for acute kidney injury (AKI) have recently become a subject of special attention [7]. The Acute Dialysis Quality Initiative Workgroup (ADQI) with the Acute Kidney Injury Network (AKIN) society proposed of a multistage classification of acute kidney injury, known as RIFLE-AKIN term (RIFLE is acronym from the words: Risk, Injury, Failure, Loss, End-stage renal disease) [10-12]. The aim of the study was to explore the renal function after endovascular procedure in abdominal aortic aneurysm (AAA) with accessory renal arteries. For evaluation of kidney function was applied RIFLE-AKIN classification.

\section{Methods}

54 of patients with accessory renal arteries who underwent abdominal aortic aneurysm repair were enrolled to the project. The presence of accessory renal arteries in patients with aortic abdominal aneurysm was revealed on CT scans. Endovascular aneurysm repair (EVAR) was performed in 30 patients and in the remaining 24 a classical operation. The patients were operated in the Department of Vascular and General Surgery and Angiology of the Pomeranian Medical University in Szczecin. The control group consisted of 70 patients with abdominal aortic aneurysm without additional renal arteries. Detailed analysis including the type of repair of aortic abdominal aneurysm, the number of patients undergoing, and epidemiological characteristics of the examined groups are presented in Table 1. The inclusion criteria for the study were: size of aneurysm larger than $5.5 \mathrm{~cm}$ or an aneurysm smaller than $5.5 \mathrm{~cm}$ but growing more than $1.0 \mathrm{~cm}$ per year. Patients

*Corresponding author: Zietek Z, Department of General Surgery and Transplantology, Pomeranian Medical University, Szczecin, Poland, Tel: 503502735 . E-mail: zzietek@poczta.onet.pl

Received May 15, 2018; Accepted May 21, 2018; Published May 25, 2018

Citation: Zietek-Czeszak A, Gutowski P, Zietek Z (2018) Accessory Renal Blood Vessels as the Potential Risk Factor of Renal Failure for Endovascular Treatment in Abdominal Aortic Aneurysm. J Clin Case Rep 8: 1116. doi: 10.4172/2165 7920.10001116

Copyright: (c) 2018 Zietek-Czeszak A, et al. This is an open-access article distributed under the terms of the Creative Commons Attribution License, which permits unrestricted use, distribution, and reproduction in any medium, provided the original author and source are credited. 
were excluded from the study with the symptoms of inflammatory aortic aneurysm. The following tests were used to assess renal function: lab tests included concentration of creatinine and urea in blood plasma, and vital sign measurements like a glomerular filtration rate (GFR) and urine output per hour (UO) [13,14]. These parameters were used to assess only three stadia of RIFLE-AKIN classification: R (Risk), I (Injury) and F (Failure) [13,14]. Stadium R (Risk) can be recognized if postoperative concentration of creatinine increases 1.5 fold to preoperative value, GFR decreases $25 \%$ to baseline value or urine output lowers than $0.5 \mathrm{ml} / \mathrm{kg} / \mathrm{h}$. Diagnosis of stadium I (Injury) can be confirmed if postoperative concentration of creatinine increases 2 -fold to preoperative, GFR decreases $50 \%$ to baseline value or urine output lowers than $0.5 \mathrm{ml} / \mathrm{kg} / \mathrm{h}$ and is lasting at least 12 hours. Stage F (Failure) - can be diagnosed when postoperative concentration of creatinine increases 3-fold to preoperative value, GFR decreases $75 \%$ to baseline value or urine output lowers than $0.3 \mathrm{ml} / \mathrm{kg} / \mathrm{h}$ [15]. Normally distributed data were presented as the mean $(\mathrm{X}) \pm$ standard deviation (SD). The statistical hypothesis of EVAR's safeness in the treatment of aortic abdominal aneurysm in the presence of accessory renal arteries was analysed with Student's t-test. The ANOVA test was applied to analysis the differences among group means. The ANCOVA test was utilized to correct for confounding and increase of precision of an estimated differences. Statistical significance was approved at $\mathrm{p}<0.05$.

Ethical Committee of Pomeranian Medical University approved the project. All subjects after having read the information leaflet about the study gave informed consent to participate in the project.

\section{Results}

The analysed parameters in the group of patients with accessory renal arteries operated EVAR are presented in Table 2 . The preoperative mean concentration of urea, creatinine, GFR, and urine output in the patients were in the normal lab range. After EVAR procedure was observed a slight postoperative increase in the concentration of creatinine and urea, and little decrease in GFR and urine output. However, statistical calculations of above changes evaluated by Student's -test shown that none of postoperative value reached the statistical significance level. The examined parameters were also compared between all groups of patients (Table 3).

The concentration of urea was the lowest in the group of EVAR's patients $(45.114 \mathrm{mg} / \mathrm{ml})$. The concentration of creatinine was the lowest $(1.13 \pm 0.3 \mathrm{mg} / \mathrm{dl})$ in the control group. The urine output and GFR $\left(0.60 \pm 0.1 \mathrm{ml} / \mathrm{kg} / \mathrm{h}\right.$ and $61 \pm 21 \mathrm{ml} / \mathrm{kg} / 1.72 \mathrm{~m}^{2}$ respectively $)$ were the lowest in the group of patients with ARAs who underwent classical approach. The values of examined parameters in all group of patients were in normal lab range and statistical analysis performed by ANOVA test did not demonstrate significant differences between them.

The examined parameters of the patients who underwent EVAR

\begin{tabular}{|c|c|c|c|}
\hline \multirow{3}{*}{ Clinical epidemiologic data } & \multicolumn{3}{|c|}{ Groups of patients and method of treatment } \\
\hline & \multicolumn{2}{|c|}{ With ARAs } & \multirow{2}{*}{$\begin{array}{c}\text { Without ARAs } \\
\text { Classical surgery } n=70\end{array}$} \\
\hline & EVAR procedure $n=30$ & Classical surgery $n=24$ & \\
\hline Mean age & $72 \pm 14$ & $79 \pm 11$ & $67 \pm 14$ \\
\hline Smokers & $23(78 \%)$ & $20(85 \%)$ & $38(54 \%)$ \\
\hline Hypertension & $20(68 \%)$ & $18(74 \%)$ & $40(57 \%)$ \\
\hline Hypercholesterolemia & $17(57 \%)$ & $16(65 \%)$ & $31(44 \%)$ \\
\hline Stroke & $1(2 \%)$ & $1(1 \%)$ & $1(1 \%)$ \\
\hline Myocardial infarction & $2(6 \%)$ & $2(5 \%)$ & $3(4 \%)$ \\
\hline Atherosclerosis of lower limbs & $10(32 \%)$ & $10(40 \%)$ & $20(28 \%)$ \\
\hline Diabetes mellitus & $8(25 \%)$ & $7(30 \%)$ & $16(22 \%)$ \\
\hline BMI & $32 \pm 4$ & $30 \pm 5$ & $31 \pm 4$ \\
\hline
\end{tabular}

Table 1: Clinical and epidemiological characteristics of patients treated by endovascular or classical procedure with presence of accessory renal arteries or without ones ARAs - accessory renal artery, EVAR - endovascular aneurysm repair.

\begin{tabular}{|c|c|c|}
\hline \multirow{2}{*}{ Parameter } & Preoperative & Postoperative \\
\cline { 2 - 3 } & $\mathbf{n} \pm \mathbf{S D}$ & $\mathbf{X} \pm \mathbf{S D}$ \\
\cline { 2 - 3 } & $\mathbf{n}=\mathbf{3 0}$ & $45.1 \pm 14$ \\
\hline Urea $[\mathrm{mg} / \mathrm{dl}]$ & $43.7 \pm 12$ & $1.21 \pm 0.5$ \\
\hline Creatinine $[\mathrm{mg} / \mathrm{dl}]$ & $1.06 \pm 0.2$ & $66 \pm 25$ \\
\hline GF $\left[\mathrm{ml} / \mathrm{min} / 1.72 / \mathrm{m}^{2}\right]$ & $69.9 \pm 18$ & $\mathrm{p}=0.1678$ \\
\hline
\end{tabular}

Table 2: Parameters in patients with accessory renal arteries (ARAs), before and after endovascular procedure for abdominal aortic aneurysm (EVAR) (X - mean, SD standard deviation, $\mathrm{p}$ - statistical significance according to Student's t-test).

\begin{tabular}{|c|c|c|c|c|}
\hline \multirow{5}{*}{ Examined parameter } & \multicolumn{3}{|c|}{ Group of patients } & \multirow{5}{*}{ p } \\
\hline & \multicolumn{2}{|c|}{ With ARAs } & \multirow{2}{*}{$\begin{array}{l}\text { Control/no ARAs/ } \\
\text { Classical method }\end{array}$} & \\
\hline & EVAR prpocedure & Classical method & & \\
\hline & $X \pm S D$ & $X \pm S D$ & $X \pm S D$ & \\
\hline & $n=30$ & $n=24$ & $\mathrm{n}=70$ & \\
\hline Urea [mg/dl] & $45.1 \pm 14$ & $46.1 \pm 18$ & $46 \pm 16$ & $p=0.8549$ \\
\hline Creatinine [mg / dl] & $1.21 \pm 0.5$ & $1.26 \pm 0.6$ & $1.13 \pm 0.3$ & $p=0.5167$ \\
\hline GFR ml/min/1.72 m2] & $66 \pm 25$ & $61 \pm 21$ & $69 \pm 23$ & $p=0.6723$ \\
\hline $\mathrm{UO}[\mathrm{ml} / \mathrm{kg} / \mathrm{h}]$ & $0.61 \pm 0.1$ & $0.60 \pm 0.1$ & $0.64 \pm 0.1$ & $p=0.7987$ \\
\hline
\end{tabular}

Table 3: Analysed parameters in all groups of patients both with and without accessory renal arteries after EVAR and classical approach for abdominal aortic aneurysm. Patients without accessory vessels composed the reference group (X - mean, SD - standard deviation, $p$ - statistical significance according the ANOVA test). 


\begin{tabular}{|c|c|c|c|c|}
\hline \multirow{2}{*}{ Analysed parameter } & \multirow{2}{*}{ Factual postoperative value } & \multicolumn{3}{|c|}{ The expected value for the stage } \\
\hline & & Risk & Injury & Failure \\
\hline Creatinine [mg /dl] & 1.21 & 1.59 & 2.12 & 3.18 \\
\hline GFR $\left[\mathrm{ml} / \mathrm{min} / 1.72 \mathrm{~m}^{2}\right]$ & 66 & 52.4 & 35 & 18 \\
\hline UO [ml/kg/h] & 0.61 & $0.49(6 \mathrm{~h})$ & $0.49(12 \mathrm{~h})$ & 0.3 \\
\hline
\end{tabular}

Table 4: The expected value of the parameter calculated according to criteria of RIFLE-AKIN classification, which would allow to diagnose one of the stadium of acute kidney injury in patients subjected EVAR procedure with accessory renal arteries ARAs, in the brackets required duration of decreased urine output.

procedure with the accessory renal arteries was evaluated according to RIFLE-AKIN criteria (Table 4). As can be noticed none of postoperative parameters reached the expected value what would justified the diagnosis one of the three analysed stadia of acute renal injury. The analysis of individual measurements in each patient showed that only in three patients after endovascular procedure could have happened kidneys injury but these patients had before endovascular procedure a slightly elevated concentration of creatinine. Considering RIFLEAKIN criteria most of the patients with accessory renal arteries who underwent EVAR procedure for aortic abdominal aneurysm did not fulfil the criteria of acute kidney injury. But some of patients with a slightly increased of creatinine fulfilled the stadium Risk and Injury of this classification. Based on the ANCOVA test was shown that preoperative renal failure is an independent factor of acute renal injury after EVAR procedure with the presence of ARAs. In general, it seems that applying EVAR procedure for aortic abdominal aneurysm in patients with normal kidney function despite the presence of accessory renal arteries is a safe method and is not associated with an increased risk of acute kidney injury.

\section{Discussion}

Based on the results of this project can be suggest that EVAR procedure with accessory renal arteries is a safe method because is not associated with increased risk of renal ischemia and eventual renal failure. Similar outcomes were achieved by other authors [1627]. The authors based their conclusions on other criteria such as postoperative mortality, blood pressure control, the diameter of the trunk of accessory arteries or size of renal infarction area. But they did not apply RIFLE-AKIN classification. Some authors pointed that protection of accessory renal arteries could jeopardize for outcome of aortic abdominal aneurysm repair [21].

However, in the literature can be also found few reports highlighting the existence of an increased risk of postoperative renal failure in patients operated with EVAR in the presence of accessory renal arteries $[28,29]$. Some authors used the renal scintigraphy to evaluate to loss of kidney mass after the endovascular procedure. The authors shown an average loss of kidney mass ranged of $10-23 \%$. Their conclusion was that endovascular repair of aortic abdominal aneurysm with accessory renal arteries could be a rather safe option of treatment. However, they emphasize, that in the case of existing renal failure, qualifying patients for this method should be very careful [19]

RIFLE-AKIN classification was applied by one group of authors for evaluation of kidney function after endovascular procedure for aortic abdominal aneurysm with accessory renal arteries, but their results were in the opposite to ours [22]. The interesting experimental study, concerning the effect of EVAR on renal function with accessory renal arteries was conducted by Malgor et al. [23]. The authors carried out EVAR procedure with and without intention to protect of accessory renal arteries. Based on scintigraphy scans the authors assessed the kidney function. In both type of EVAR procedure was observed some symptoms of kidney infarction. Their conclusion was that no deteriorations of renal function was happening if kidney infarction covered less than $7 \%$ of total kidney mass. In the light of the above the authors suggest that the presence or absent of additional renal arteries have the same probability of deteriorations on kidney function after endovascular approach for repair of aortic abdominal aneurysm. Their main conclusion that accessory renal arteries should not necessarily change the strategy of the treatment $[9,23]$. In contrast to the common opinion of the superiority of classic vascular procedures for renal function, another group of authors emphasized better results of intravascular approach, but the study included patients with abdominal aortic aneurysm without additional renal arteries $[28,29]$. It is also emphasized that renal function after endovascular procedures is a cumulative effect not only of the chosen treatment procedure or the clinical dynamics of the aneurysm but may also depend on coexisting diseases [30].

Renal function after repair of the abdominal aortic aneurysm is one of the most important factors reducing adverse events associated with the repair of abdominal aortic aneurysm and a key criterion reducing post-operative morbidity and mortality. It also seems to be important for kidney function reducing the frequency of performing radiological examinations, which are more aggravating renal function, for much safer other examinations like contrast-enhanced ultrasound (CEUS) [31]. The review of the literature reveals necessity of further studies on this subject. Therefore, these studies should be intensified in the search for other factors affecting renal function after treatment of abdominal aortic aneurysms.

\section{Conclusions}

The presence of accessory renal arteries should not be a categorical criterion for rejecting this method because EVAR procedure is not significantly associated with increased risk of postoperative acute renal injury. Protection of accessory renal arteries during EVAR procedure is not absolutely required.

\section{References}

1. Chan YC, Qing KX, Cheng SW (2014) Custom-made fenestrated stent grafts to preserve accessory renal arteries in patients with abdominal aortic aneurysms. Acta Chir Belg 114: 183-188.

2. Aquino RV, Rhee RY, Muluk SC, Tzeng, EY, Carrol NM, et al. (2001) Exclusion of accessory renal arteries during endovascular repair of abdominal aortic aneurysms. J Vasc Surg 34: 878-884

3. Johnston KW (1989) Multicenter prospective study of nonruptured abdomina aortic aneurysm. Part II. variables predicting morbidity and mortality. J Vasc Surg 9: 437-447.

4. Chertow GM, Burdick E, Honour M, Bonventre JV, Bates DW (2005) Acute kidney injury, mortality, length of stay, and costs in hospitalized patients. J Am Soc Nephrol 16: 3365-3370.

5. Wald R, Waikar SS, Liangos O, Pereira BJ, Chertow GM, et al. (2006) Acute renal failure after endovascular vs. open repair of abdominal aortic aneurysm. J Vasc Surg 43: 460-466

6. Abraham CZ, Chuter TA, Reilly LM, Okuhn SP, Pethan LK, et al. (2002) Abdominal aortic aneurysm repair with the zenith stent graft: Short to midterm results. J Vasc Surg 36: 217-224.

7. Prinssen M, Verhoeven ELG, Buth, J, Cuypers PWM, van Sambeek, et al. 
Citation: Zietek-Czeszak A, Gutowski P, Zietek Z (2018) Accessory Renal Blood Vessels as the Potential Risk Factor of Renal Failure for Endovascular Treatment in Abdominal Aortic Aneurysm. J Clin Case Rep 8: 1116. doi: 10.4172/2165-7920.10001116

(2004) A randomized trial comparing conventional and endovascular repair of abdominal aortic aneurysms. N Engl J Med 351: 1607-1618.

8. Toya N, Ohki T, Momokawa Y, Shukuzawa K, Fukushima S, et al. (2016) Risk factors for early renal dysfunction following endovascular aortic aneurysm repair and its effect on the postoperative outcome. Surg Today 46: 1362-1369.

9. Antoniou GA, Karkos CD, Antoniou SA, Georgiadis GS (2013) Can an accessory renal artery be safely covered during endovascular aortic aneurysm repair? Interact Cardiovasc Thorac Surg 17: 1025-1027.

10. Schiffl H, Lang SM (2012) Update on biomarkers of acute kidney injury: Moving closer to clinical impact? Mol Diagn Ther 16: 199-207.

11. Wasung ME, Chawla LS, Madero M (2015) Biomarkers of renal function, which and when? Clin Chim Acta 14: 9-8981.

12. Lopes JA, Jorge S (2013) The RIFLE and AKIN classifications for acute kidney injury: A critical and comprehensive review. Clin Kidney J 6: 8-14.

13. Matuszkiewicz-Rowińska J (2008) Acute kidney injury and RIFLE classification: Advantages and disadvantages. Nefrol Dial Pol 12: 248-250.

14. Bellomo R, Kellum JA, Ronco C (2007) Defining and classifying acute renal failure: From advocacy to consensus and validation of the RIFLE criteria. Intensive Care Med 33: 409-413.

15. Mehta RL, Kellum JA, Shah SV, Molitoris BA, Ronco C, et al. (2007) Acute kidney injury network: Report of an initiative to improve outcomes in acute kidney injury. Crit Care 11: 31

16. Greenberg RK, Chuter TA, Lawrence-Brown M, Haulon S, Nolte L (2004) Analysis of renal function after aneurysm repair with a device using suprarenal fixation (Zenith AAA Endovascular graft) in contrast to open surgical repair. $J$ Vasc Surg 39: 1219-1228.

17. Greenberg RK, Sternbergh WC, Makaroun M, Ohki T, Chuter T, et al. (2009) Fenestrated investigators. Intermediate results of a USA multicenter trial of fenestrated endograft repair for juxtarenal abdominal aortic aneurysms. J Vasc Surg 50: 730-737.

18. Greenberg JI, Dorsey C, Dalman RL, Lee JT, Harris EJ, et al. (2012) Long term results after accessory renal artery coverage during endovascular aortic aneurysm repair. J Vasc Surg 56: 291-296.

19. Dzieciuchowicz J, Espinnosa G, Diaz CV, lavilla Rova El, Lostan IA (2012) Renal function in patients treated with abdominal aortic stentograft implantation with an intentional occlusion of accessory renal artery. Ann Vasc Surg 26: 299-305.

20. Karmacharya J, Parmer SS, Antezana IN, Fairman RM, Woo EV, et al. (2006)
Outcomes of accessory renal artery occlusion during endovascular aneurysm repair. J Vasc 43: 8-13.

21. Kim B, Donavre CF, Hansen Cl, Aziz I, Walot I, et al. (2004) Endovascular abdominal aortic aneurysm repair using the AneuRx stent graft impact of excluding accessory renal arteries. Ann Vasc Surg 18: 32-37.

22. Bakr NA, Bak G, Torsello GA, Pitoulias K, Stavroulakis M, et al. (2016) Preservation of clinically relevant accessory renal arteries in infrarenal AAA patients with adequate proximal landing zones undergoing EVAR. J Endovasc Ther 23: 314-320.

23. Malgor RD, Oderich GS, Vritska TJ, Kalra M, Gloviczki P, et al. (2013) A case-control study of intentional occlusion of accessory renal arteries during endovascular aortic aneurysm repair. J Vasc Surg 58: 1467-1475.

24. Kaplan DB, Kwon CC, Marin ML, Hollier LH (1999) Endovascular repair of abdominal aortic aneurysm in patients with congenital renal vascular anomalies. J Vasc Surg 30: 407-415.

25. Blankensteijn JD, de Jong SE, Prinssen M, van der Ham AC, Buth J, et al (2005) Two-year outcomes after conventional or endovascular repair of abdominal aortic aneurysms. N Engl J Med 352: 2398-2405.

26. Saratzis A, Melas N, Mahmood A, Sarafidis P (2015) Incidence of Acute Kidney Injury (AKI) after Endovascular Abdominal Aortic Aneurysm Repair (EVAR) and impact on outcome. Eur J Vasc Endovasc Surg 15: 1078-5884.

27. Hua HT, Cambria RP, Chuang SK, Stoner MC, Kwolek CJ, et al. (2005) Early outcomes of endovascular versus open abdominal aortic aneurysm repair in the National Surgical Quality Improvement Program-Private Sector (NSQIP PS). J Vasc Surg 41: 382-389.

28. Siracuse JJ, Gill HL, Graham AR, Schneider DB, Connolly PH, et al. (2014) Comparative safety of endovascular and open surgical repair of abdominal aortic aneurysms in low risk male patients. J Vasc Surg 60: 1154-1158.

29. Gawenda M, Brunkwall J (2008) Renal response to open and endovascular repair of abdominal aortic aneurysm: A prospective study. Ann Vasc Surg 22 $1-4$

30. Brown LC, Brown EA, Greenhalgh RM, Powell JT, Thompson SG (2010) UK EVAR Trial Participants: Renal function and abdominal aortic aneurysm (AAA): The impact of different management strategies on long-term renal function in the UK EndoVascular Aneurysm Repair (EVAR) Trials Ann Surg 251: 966-975.

31. Ciccone MM, Cortese F, Fiorella A (2011) The clinical role of contrast-enhanced ultrasound in the evaluation of renal artery stenosis and diagnostic superiority as compared to traditional echo-color-Doppler flow imaging. Int Angiol 30: 135-139. 